Journal of Social and Development Sciences

Vol. 3, No. 5, pp. 152-160, May 2012 (ISSN 2221-1152)

\title{
Virtual Applications and Real Problem: Education and Higher Education in Iran
}

\author{
Mohamed Tavakol \\ University of Tehran, Iran \\ mtavakol@ut.ac.ir
}

\begin{abstract}
Important aspects of Education and Higher Education such as Flexibility, Access, Relevance, Privatization, Human Resources, National Development, Innovation, and Globalization are all subject to a radical transformation as a result of substantial changes and new circumstances occurred and are occurring with the introduction into and application of information technologies (IT) in this realm. It was justifiably expected that these transformations would also occur in the Iranian Education and especially Higher Education. The paper, after outlining the new expectations from and challenges in Education and Higher Education throughout the world and the rise of new perspectives for them, will focus on major developments in virtual Education and Higher Education in Iran-considering the framework of recent socio-economic demands and expectations. Based on a descriptive method, and with the use of available official data, though critically, an overview of e-learning in Iran will be portrayed and its recent developments, quantitatively and qualitatively, resulted from the introduction of IT into the pre-university and university systems (as an important part of national TAKFA plan and its aftermath) would be reviewed, and the achievements and shortcomings during the last ten years analyzed and discussed. It will be demonstrated in this paper that the aptitude for and expectation from virtual education is very high in the country. The paper tries to shed light on why the gap between what is realized and what is expected is so deep.
\end{abstract}

Keywords: ICT, Virtual, Education, Higher Education, Iran

\section{Introduction}

The expansion of information technologies and their consequences on the lives of individuals and societies, in general, and the introduction of ICTs into education in particular, have been important issues occupying minds and attracting interests. Putting students and teachers in a virtual environment and making them familiar with these technologies, then, for many, has become a necessity throughout the globe. For this purpose, students, as future mature citizens, are trained to get ready for living in the so-called Information Society. Along with the development of ICTs, both developed and developing countries have employed these technologies in their education systems; but there has been a difference in their objectives. While in developed countries the objectives in the application of ICTs in education have been the diversification of educational methods, as well as providing a new framework to promote the quality, variety, and depth of educational programmes, in the developing countries ICTs have been, at best, an instrument to expand the access to general education and reduce the physical and geographical gap, especially in the rural and discrete areas. Virtual education programs in most of the developing countries, and even in some of developed countries, are aimed at training future teachers, to recognize the needs of the Information Age for new learning skills, to recognize virtual learning environments, and know how to use the ICT tools and processes. Having made these general remarks, in what follows we, on the one hand, refer to the facts and figures in the Iranian society which are supportive to, and demanding of, virtual education and higher education, and, on the other, point at the unrealized capacities and slow pace of the introduction of e-learning in the country. In the later sections, we try to understand why this gap continues to exist.

\section{Literature Review}

Let us start with the definition of virtual education. It means instruction in a learning environment where teacher and students are separated by time and/or space and the teacher provides course content through ICT based methods such as Internet, multimedia resources, and videoconferencing. Students get the content and communicate with the teacher via the same media (Kurbel, 2001). Among the sources that have taken up 
the task of reviewing the development of virtual learning, historically, Wikipedia's has done the job thoroughly, by going through the achievements period by period, year by year, and even month by month at times. It provides a chronological account of the major developments with the relevant particulars, the venue, and the authors and inventors (Wikipedia, 2012a). There is also a rich literature on the development of virtual education, its pushing factors, its challenges, and its achievements and consequences, at the universal level and at the level of regions and countries (Rivoltella, 2008; Rabi, 2005; Gulanti, 2008). In addition, there are case studies showing the place e-learning has occupied in different parts of the world. Massy and Ward tell us about the trends of virtual education in Europe, underlying the fact that e-learning, as early as 2002, had the share of between $8 \%$ and $16 \%$ of the whole education in the EEC- except in Greece and Sweden (Massy and Ward, 2002). This is not unique to the West. For example, Malaysia as an East Asian nation has advanced in virtual higher education so that the enrolment number of online students at one of its universities (UiTM) is bigger than the sum total of virtual higher education enrolment in Iran as a whole. Regarding Iran, the literature on virtual education both at pre-university and university levels is relatively poor. The sources for statistics and information are limited and mostly restricted to official reports, which, at times, are not consistent. Even fewer works can be found to study, analytically, the subject matter and explain the situation in relation to other socio-cultural, politico-economic, and developmental problems and realities. Some writers, however, have listed a number of existing features of virtual education in Iran (Montazer and Bahreininejad, 2004; Kiani, Farrokhi and Jalali, 2005; Yaghoubi et al. 2008) or have reported the results of their case studies and fieldworks on a specific topic within a certain e-learning centre or unit (Hejazi and Dilmaghani, 2005; Yaghoubi et al. 2008; Fariborzi and AbuBakar, 2011). Very few authors have tried to put different aspects, parameters, and obstacles within the Iranian VE together and discuss them under different classifications (Masoumi, 2010; Khamesan, 2010), however the outcomes have remained descriptive, and , therefore, they do not provide any comprehensive and systematic analysis of the development of virtual education and its present status. We have tried, as the main objective of this paper, to overcome this deficiency and search for the reasons why virtual education in Iran is not what is expected to be. We have put virtual education data and statistics, as well as factors hindering e-learning, in connection to surrounding realities and processes, to help us reaching an explanatory and pathological understanding of the current situation.

\section{Methodology}

The paper combines descriptive, comparative, and analytic methods. It is partly descriptive and informative and presents statistics and data available from official reports and documents, national and sectoral plans and programmes. In some parts, it is comparative and refers to data from other countries experiences, and presents deductive argumentations. In some other parts, it is analytic and explanatory, and uses the "observation with participation" method. The latter was made possible and valuable in view of the fact that the author, for more than two decades, has been, both deeply involved in the educational system in his capacity as an academic and researcher, and, active in the policy-making circles. Moreover, the paper has benefitted from analytical sources and publications in universal and general matters, and in national arguments.

Background Information: With a population of about 75 million, and 36.5 million Internet users, Iran occupies the first place in the Middle East (ITU, 2011). It means about 50\% of the whole population of the country works, or is familiar, with the Internet, and this makes up $47 \%$ of the whole Internet-users in the Middle East. The world place of Iran in this respect is 11th, out of 195 countries (Internet World Stats, 2011). In the same line, as far as the number of ISPs is concerned, Iran is $9^{\text {th }}$ among 165 countries, in number of websites, stands $58^{\text {th }}$ in the world, in computer science application output ranks $17^{\text {th }}$, and in quality of math and science education is $35^{\text {th }}$ (International Rankings of Iran, 2012) .These show that the virtual space is widely present in Iran and can be channelled to educational matters. Moreover, education has special cultural value, and social demand for university education, in particular, is extremely high (Tavakol, 2007). According to the international sources, Iran ranks $22^{\text {nd }}$ (among 200 countries) in education enrolment at tertiary level, and among the world's top universities ranks $55^{\text {th }}$. In education budget as of total government budget, Iran's rank is $19^{\text {th }}$ (out of 161), in GDP, 18 $8^{\text {th }}$ (out of 193), and in GDP per capita, 59th (out of 166) (International Rankings of Iran, 2012). The pressure of heavy demand on higher education could be diverted by initiating serious virtual higher education. Pre-university schooling has also been subject to difficulties in recent years 
in coping with heavy demands, forcing schools to double shifts and overloaded classes. As we discuss later, the ratio of e-learning enrolment to the regular education is about $0.5 \%$ (half of one percent only). After going through the data in the following sections, we discuss the problems and try to understand the reasons, and the ways to overcome them.

Pre-University ICT-Based Education in Iran: In the turning years of the Twentieth Century, the imperatives of the age of knowledge and information and the need to follow the achievements of information technology in the country led to government's decisions to invest in the rapid expansion of information and communication technology (ICT). It was understood that ICT could help greatly in achieving specific social and economic development goals as well as in playing a key role in broader national development strategies. As a result, a national ICT agenda in Iran was drawn up and called "TAKFA". TAKFA, the general framework of National Information and Communication Technology Agenda, was considered the road map to knowledgebased development. It consisted of five major parts, namely:

- Infrastructure: Access, Security, Data Centres, Regulations, and Law.

- Commerce and Economic Services: e-Commerce, e-Banking, e-Money, etc.

- Government Services: e-Services, e-Governance, and e-Government.

- Human Resource Development, Cultural and Social Programmes: HRD and e-Education, Culture in Digital Environment.

- Employment and Industry: Industrial Development, High Tech Jobs, Industrial Parks, and SME Development (TAKFA, 2005).

The Iranian Ministry of Education (responsible for pre-university education, i.e., elementary school, middle or "guidance" school, and high school), in this connection, prepared a charter to guide reforms in Iran's education system with the application of ICT as one of its pillars. The Office of Planning for the Development of ICT in Education employed expert managers, developed operational programs, and defined executive projects. The following projects were implemented or were in the process of development:

A. Project of Research and Development; for reviewing the Country's education system and re-orienting it with regard to modern educational approaches to information technology.

B. Project of Training Personnel; launching this project, in its first year, resulted in the training of 120,000 teachers and specialists (Nafisi, 2003).

C. Project for equipping schools; establishing computer laboratories in 6,500 educational units, 60 teacher training centres and 40 technical institutes, in the first year of its implementation (Zamani, 2010).

D. Project for creating electronic content; it dealt with the contents as offered on the World Wide Web, and was divided into three sections: information, services, and educational resources.

E. Project for a National Network of Schools; began in 2001, connecting some 1,200 high schools in 6 provinces (Ministry of Education, 2003).

ICT application in education in Iran had three major dimensions; teacher training, inter-school networking, and educational content. As far as teacher training is concerned, in the first phase of the project (years 20023) some 70,000 teachers and 7,000 heads of schools' computer labs did courses dealing with basics of operating system, IT-based learning, and trainings to use the Internet. In the following two years, the training continued and, as documents report, some 42 million person/hour training were provided (Supreme Council of ICT, 2005). It is reported that in its initial stages the programmes were doing quite well, but later with the private sector taking over their execution in provinces, the plan was slowed down and carried out incompletely and discretely.

As to school networking, the National Network of Schools, ROSHD, was introduced to strengthen and promote national IT-based course-work programme. By implementing the project, the ratio of computer per secondary level students grew from 1.295 to 1.60, and training centers accessed 6950 sets of PIV, 25800 PIII computers, 6550 printers and 6550 scanners (Supreme Council of ICT, 2005). As far as content production is concerned, two major digital productions were to be made available; the supply of school texts in PDF format, and some of textbooks in CDs. In addition to school texts, there were other content production projects, for example Elearning Software for Vocational Training Organization of IRAN --managed by the Ministry of Labor and Social Affairs. Whether the contents produced met the expected standards in quality and quantity was another problem (Safavi, Baveghar, and Ghaffari, 2006; FAA, 2005). We had a quick review of the major 
Iranian educational projects, planned or partially implemented by the government. However, a country with some 18 million students needs to do much more, considering the ICT facilities known or available in the country, the general aptitude of young students, the widespread articulation of need for change in education, and the country's socio- economic realities and potentials (Montazer and Bahreininejad, 2004). The newly made available report on the situation of ICT application in the Iranian pre-university education admits the shortcomings. These include connection to the national intranet by only 15,000 schools rather than the 50,000 target foreseen to be realized in the fourth National Development Plan, content production reaching only $15 \%$ of the target, and many other indicators marked as "unknown" (Statistics and Information and Communication Technology Centre, 2011).

Virtual Higher Education in Iran: Regarding virtual or ICT-based higher education in Iran, an important differentiation should be made. A number of institutions of higher education have integrated IT into the academic services they provide to their students and academic staff-but their structure, and its functioning, are conventional, i.e. non-virtual. A lesser number of institutions of higher education have been formed, as a whole, as a virtual or pseudo-virtual higher education, or allocated part of their setting to this type of education. Even these have been only busy with teaching and learning-and almost none has dealt with virtual research (and VRE) (Tavakol: 2009a). In contrast to what is expected, and is experienced in advanced countries, the virtual institutions of higher education in Iran are not free from the hard regulations, or innovative, in their requirements, procedures, academic content and programs, and many other affairs. They are supposed to follow, like conventional universities, the centralized and uniform regulations and procedures. However, the first virtual higher education institution was formed, in 2004, inside the wellestablished conventional University of Shiraz, the capital of the central province of Fars. It started with some 100 students only (Masoumi, 2010). Soon after Shiraz few other virtual higher education centers were formed. The number reached to 13 centers in 2007 with the student population of 8,000-and to 26 centers (to include 6 Medical Sciences University centers) with the total enrolment of some 19,000. When you compare this number with that of over 4.2 million students enrolled at conventional higher education institutions it means too little-despite its high growth rate since its start. The table below shows the names of the existing virtual education centers followed by their enrolment, differentiated by the degree levels offered by each center.

\section{Results and Discussion}

From our study the following results can be drawn: In Iran, virtual education, and specially higher education, is still considered more as a luxury entity - this is the case by both policy and decision makers, and, the public. As a result, it is not taken seriously, and has not been established on equal footing, and as a valuable alternative to conventional education. It is treated as an auxiliary type education for an individual who has no other choice. If not explicitly and officially, in reality virtual higher education is less credible than the conventional one-and naturally attracts less talented and qualified students. This is the widespread view of students, families, and even, in effect, of the government. Virtual higher education is still fed and managed as a "parasite" to conventional universities and regular higher education centers; in terms of the headquarters, buildings, equipments, budget, personnel, academic staff, and legal arrangements. This is particularly true for the great majority of public virtual universities. Consequently they do not have well-trained instructors for ICT-based learning, sufficient and well-prepared educational content, independent administration and personnel, distinct and flexible procedures, and independent organizational authority differentiated from the conventional higher education. Internet problems and shortcomings; Internet speed in Iran, according to the Net Index, ranks $167^{\text {th }}$ out of 168 countries of the world. Iran's position in uploading and downloading is one of the worst, occupying the $172^{\text {nd }}$ place in the world (Net Index by Ookla, 2010). Iranian Communication Company itself reports that out of the whole Internet-users of the country only 700,000 benefit from the high speed ADSL and the rest(98\%) use the low-speed dial up option (Sarabpour, 2011). International sources estimate Iran's digital opportunity index to be $105^{\text {th }}$ (out of 120 countries) with a total number of broadband internet users ranking $44^{\text {th }}$ among 48 countries (International Rankings of Iran, 2012).The Internet price in Iran is one of the most expensive in the world especially when the quality and speed are considered (Tabnak, 2011, Mehr, 2011, Aftab, 2011). Deficiencies are present in both ICT "hardware" and "software" of Iranian virtual higher education; in terms of equipment, regulations, procedures, and preparations. The virtual higher education concept as understood worldwide is not internalized in Iran and its requirements are not well met. 
For example the exams are given in classic "by presence" form-and not on-line. The courses are handled at times in a semi-classic form on CDs--and the tele-conferencing, on-line \& networked interaction and participation by students and teachers is replaced by face-to-face classes. Despite the fact that a considerable budget had been allocated to virtual education in the past years, with the absence of an integrated and comprehensive plan, most of it has gone to hardware purchases, and very little to multi-media content production.

Virtual universities / higher education centers and their enrolments

\begin{tabular}{|c|c|c|c|c|}
\hline \multirow[t]{2}{*}{ Higher Education Institution } & \multicolumn{4}{|c|}{ Educational level } \\
\hline & Bachelors & Masters & Ph.D. & Total \\
\hline University of Isfahan & 14 & 320 & & 334 \\
\hline Tarbiat Modarres University & & 168 & & 168 \\
\hline Azarbayjan Tarbiat Moallem University & 266 & & & 266 \\
\hline University of Tehran & 382 & 1300 & & 1682 \\
\hline Sistan \& Baloochestan University & & 43 & & 43 \\
\hline Shahid Beheshti University & & 232 & 7 & 239 \\
\hline University of Shiraz & 3453 & 861 & & 4314 \\
\hline Isfahan University of Technology & 204 & & & 204 \\
\hline Amir Kabir University of Technology & & 2019 & & 2019 \\
\hline Khaje Nasir Toosi University of Technology & 781 & 27 & & 808 \\
\hline Tabriz Sahand University of Technology & 721 & & & 721 \\
\hline Iran University of Science \& Technology & 1002 & 612 & & 1614 \\
\hline Ghom University & 1 & 290 & & 291 \\
\hline Isfahan University f Medical Sciences & & 52 & & 52 \\
\hline Tabriz University of Medical Sciences & & 13 & & 13 \\
\hline Tehran University of Medical Sciences & & 107 & & 107 \\
\hline Shahid Beheshti University of Medical Sciences & & 158 & & 158 \\
\hline Shiraz University of Medical Sciences & & 26 & & 26 \\
\hline Kerman University of Medical Sciences & & 4 & & 4 \\
\hline Payame Noor University & 275 & 30 & & 305 \\
\hline University of Hadith Sciences & 2115 & 350 & & 2465 \\
\hline Virtual Electronic Higher Education Institute & 444 & & & 444 \\
\hline $\begin{array}{l}\text { Faran Virtual Electronic Higher Education } \\
\text { Institute }\end{array}$ & 949 & & & 949 \\
\hline $\begin{array}{l}\text { Noortooba Virtual Electronic Higher Education } \\
\text { Institute }\end{array}$ & 1177 & 104 & & 1281 \\
\hline Karaj Farabi Higher Education Institute & & 165 & & 165 \\
\hline $\begin{array}{l}\text { Tehran Mehr Alborz Higher Education } \\
\text { Institute }\end{array}$ & & 285 & & 285 \\
\hline Total & 11784 & 7166 & 7 & 18957 \\
\hline
\end{tabular}

One of the features of virtual education systems is networking-to exchange knowledge and experience, to promote cooperation, and to bring dialogue, livelihood, and socialization into the process of learning. In recent years, in addition to the national ICT-based educational systems, there has been an extension of international, and regional networks based on ICTs; to name a few we should mention IEARN, ORACLE (Think Quest), and MONDIALOGO(Tavakol:2009b). This valuable channel has not been used enough to develop Iranian virtual education. As evidence; following the successful establishment and functioning of the Avicenna virtual university network encompassing the Mediterranean countries of Southern Europe and Northern Africa, decisions were taken to have the Avicenna II (or Farabi) network formed in Iran to cover Central Asia as well. UNESCO approved it and the countries concerned. This plan, however, reached nowhere, and has remained, for a decade on paper only. One of the aims or outcomes of virtual higher education, universally, have been to make higher education more affordable and accessible, especially for the lower strata and the marginal groups. This has not been realized in Iran, especially as far as the costs are concerned. The factors that play a role in the stagnation of private and public virtual education in Iran are different. The public 
virtual education suffers from the lack of firm decisions for the development of e-learning; even at times is reluctant to it. The private virtual education does not welcome it normally due to the lack of necessary means, and sufficient resources and possibilities by its own and cannot afford them. In parallel to the fact that virtual education is, quantitatively and qualitatively, close to nothing in the atlas of Iranian education $(0.5 \%$ of the whole education, compared to $8-16 \%$ in Europe), Iran shows more or less similar rankings in e-readiness (68 ${ }^{\text {th }}$ among 70 countries in the world), digital opportunity index ( $105^{\text {th }}$ among 120 countries), and Globalization Index (62 $62^{\text {nd }}$ among 62 countries in the world). Even if we do not relate cause and effect relationship between them, the prominent role of education in this set cannot be compromised. It is a fact that the masses of youth and school pupils have approached information technologies to learn in a selflearning style what they could not acquire from the official classic schooling. This critical mass is growing bigger and bigger in size and gets increasing depth and width of general knowledge and at times even specialized knowledge. It is not an exaggeration if we say that the youth have gone ahead of the education system. The implications and consequences of such a phenomenon cannot be easily by-passed, in future. This generation is not satisfied with traditional methods and materials, the classroom-teacher model, and individualistic styles and dogmatic obedience. In addition, this can heavily affect the future changes not only in education but also in other realms in the greater society.

These necessitate the change in policy. However, the latter has gone nowhere in a bureaucratic and manipulative Administration (Moosavi and Pazooki, 2006). A change is essential both within the education and higher education, and between them, the society-, and its different parts, sectors, institutions, etc. It is particularly so if higher education is concerned with the new expectations of social relevance, equity, and national development (Tavakol, 2007). One of the avenues for change, and to test the changes, in education is the development of virtual education. We have already mentioned some of the capacities and advantages Iran enjoys in this respect. The status of Iran in the ICT indicators is one of them. The Country's educational possibilities and circumstances are the other. Earlier, we indicated that education and higher education have special cultural values in the Iranian society and culture, and social demand for higher education is extremely high. We should remember that the population of the Country is about 75 million out of which a high percentage is the youth for whom the regular universities do not have enough capacity. Moreover a sizable part of the higher education applicants (present students or potential students) are either public or private sector employees who cannot attend the classic HE fully because of their job obligations, or are from the marginal strata of women and girls, ethnic groups and minorities who are not allowed to go to educational centres, or are from the rural and discrete areas who have no access to or cannot afford classic HE. Virtual education with its flexibilities can solve their problems. Economically speaking this demand is affordable when, as we saw, in education budget as of total government budget, Iran ranks19 ${ }^{\text {th }}$ (out of 161 countries), in GDP, $18^{\text {th }}$ (out of 193), and in GDP per capita, 59th (out of166). Iranian families' zeal for the university education of their children, in effect, has been imposing tremendous pressure on classic higher education sector to expand rapidly and mushroom wisely. We should remind the reader that the Iranian higher education enrolment in 1990 was around 600,000, in 2000 became about 1,600,000, and in 2011 reached over 4,200,000 (IRPHE, 2011). This pressure, however, could be relaxed by initiating a serious virtual higher education. The same is true regarding pre-university schooling, which, in recent years, has forced schools to function in double shifts and overload their classes in primary, secondary, and high schools. It should be added that the demand for education, and particularly for higher education, is not merely a social demand, or a family push, but it is also a prerequisite for national development, to supply the necessary skilled labour force and educated manpower, according to the classic approach to development, and to facilitate and promote empowerment, participation, and networking, especially among the marginal strata and groups, and contribute to the realization of good governance and civil society, according to the new approach (Castells, 2000).

We should also add here that for many critics of the present Iranian educational programmes, from experts to the students themselves, virtual education has been considered as a framework in which their desire for innovation and change of the old and static educational content and procedures may come true. Against this background, the big question is why, with the existence of such a favorable context, and with the presence of internal and external justifications; population size and growth, social demand, development requirement, financial resources, technical possibilities, human resources, and ICT facilities, nationally and internationally, virtual education and higher education in Iran are so weak, small, underdeveloped, and limited? In our view, 
there is no single factor, or even a limited number of factors, to be taken responsible for this situation. There is rather an interrelated set of factors and parameters, which play role, though as can be implicitly noticed, some of them are more radical and crucial. In addition to the general obstacles discussed above, which were mostly related to the social system as a whole, the major factors within the education system leading to the stagnation or lack of enough speed and coverage of ICT-based education and virtual higher education in Iran may be summarized as follows:

A. Conservative attitudes-- including in the education and even in the higher education systems. In recent years, it is shown, by policy-makers and top-level actors, both, to be hard to dare and have courage to decide and implement educational changes necessary for a serious ICT application. Oversensitivity to, and control over, educational matters by the system extends to all realms of organizational, managerial, communicational, and content-production matters-including in the ICTbased education.

B. Lack of a comprehensive ICT-based educational policy to which the government is practically committed.

C. Weakness of IT-literacy among policy-makers, managers, and teachers. This and the lack of a complementary and orchestrated set of software, hardware, brain-ware, and management, and as a result a non-structured and partial introduction of ICTs to educational institutions, are reasons why not even the minimum expectations are fulfilled.

D. Obstacles to Internet connectivity and networking; the low speed, downloading limitations, added to backbone-hardware-software deficiencies, act as great barriers, and overshadow the high position of the Country regarding the number of Internet-users and ISPs.

E. Adoption of parallel networks and programmes in ICT application has led to the setting up of different and sometimes inconsistent digital systems supposedly aimed at the same objective.

F. Lack of certainty and confidence in projects initiated by the education and to some extent by the higher education administration, along with oscillations, seasonal support or retraction, in addition to the inefficiency of the communication backbone and networking, lack of enough ICT facilities, and shortage of sufficient software in the Persian language especially at pre-university education level, have made the introduction of ICT into the education and higher education systems inefficient.

\section{Conclusion and Recommendation}

To sum up, the traditional outlooks, the static structures, the over-dominance of classic methods and conservative attitudes, conventional contents, the dry bureaucracy and poor management, the lack of a comprehensive e-learning policy, the lack of motif for and belief in change, the lack of enough investment on ICT backbone-hardware-software for VE, and the low-kept Internet speed and other connectivity problems((THE REAL PROBLEMS)) have altogether hindered the realization of the advantages expected from the application of information and communication technologies in education and higher education ((THE VIRTUAL)). In view of the data, reviews and critiques, analyses and discussions brought in different sections of this paper we can come up with the following set of recommendations. We think the realization, and effective functioning, of a serious virtual education and higher education in Iran depends on:

The reform within the cultural outlook regarding education in general and e-learning in particular-to allow diversification and flexibility.

- The introduction of a new educational system, to surpass the traditional education system supported by vested interest groups, and to promote critical thinking.

- Improvement of ICT infrastructures and further investment in e-learning hardware, software, brainware, and management.

- Mobilization, through well prepared publicity programs, to address decision-makers and managers of the public and private educational centres and universities, as well as the general public, and inform them of the achievements and advantages of virtual education as a better alternative (in certain cases) to classic education.

- Encouraging teachers, professors, and researchers to approach more positively the virtual settings and provide them the ways and the means to further familiarize and benefit from ICTs achievements.

- Making decision to use international theoretical and applied experiences in the field of virtual education, and networking with the specialized centres and organizations in other countries

Without these, ICT application remains at a ceremonial, lucrative, and superficial level. The success story of 
virtual education and higher education in Iran starts, in our view, when the previously mentioned obstacles are overcome. Then and only then the road would be ready to embark on a journey when in addition to the pieces prepared, the investments provided, and the attempts made, there exists a comprehensive plan, a sincere cause, a firm decision, and a courage to move ahead.

\section{References}

Castells, M. (2000). The rise of the network society, the information age: Economy, society and culture, $I$, Cambridge, MA; Oxford, UK: Blackwell

Fannavarie Ettelaa'at. (2005). Structural Changes in IT and E-learning (in Persian), FAA, spring, 22-25.

Fariborzi, E. \& Abu-Bakar, K. (2011). E-learning in Iran: Looking at Effectiveness via a Qualitative Study. IPEDR, 20, 58-63.

Gulanti, S. (2008). Technology-enhanced Learning in Developing Nations: A Review. International Review of Research in Open and Distance Learning, 9(1), 1-16.

Hejazi, A. \& Dilmaghani, M. (2005). Aligning Campus Portals with Learners Needs. Electronics Journal of Academic and Special Librarianship, 6(1-2).

International Rankings of Iran. (2012). In Wikipedia. Retrieved May 1, 2012, from http://en.wikipedia.org/wiki/ .

Internet in Iran. (2012). In Persian Wikipedia. Retrieved May 1, 2012, from http://fa.wikipedia.org/wiki/.

Internet World Stats. (2011). Cited in international rankings of Iran, Wikipedia, Retrieved May 23, 2012, from http://en.wikipedia.org/wiki/International_rankings_of_Iran.

Institute for Research in Planning and Higher Education (IRPHE). (2011). Periodic Higher Education Statistics, Tehran: IRPHE.

ITU. (2011). www.itu.int/ITU-D/ict/statistics.

Khabargozari Aftab news agency. (2011). Internet Speed in Iran. Retrieved May 12, 2012, from http://aftabnews.ir/vdcc1sqss2bq1e8.ala2.html

Khamesan, A. (2010). E-learning in Iran II. In U. Demiray (Ed.), Cases on Challenges Facing E-learning and National Development: Institutional Studies and Practices (e-book) 259-278. Eskisehir, Turkey: Anadolu University.

Kiani, M., Farrokhi, M. \& Jalali, A. (2005). Virtual Universities' Experiences in Iran. Paper presented at International Conference on Virtual University, Bratislava, Slovak Republic, and Dec 15-16, 2005. Retrieved May 1, 2012, from www.newbrunswick.academia.edu/MahsaKiani.

Kurbel, K. (2001). Virtuality on the Students' and on the Teachers' Sides: A Multimedia and Internet Based International Master Program; ICEF Berlin GmbH (Eds.), Proceedings of the 7th International Conference on Technology Supported Learning and Training - Online Education; Berlin, Germany; November 2001, 133-136---cited in Wikipedia; virtual education.

Masoumi, D. (2010). E-learning in Iran. Retrieved March 12. 2012, from www.taalim.ir /files/IRAN1.pdf.

Massy, J. H. \& Ward, T. (2002). The European E-learning Market 2002 cited in Wojna, E., Virtual Schools and the Future of Education in Globalized World. Retrieved May 5, 2012, from www.lsu.edu/faculty/jwither/Essays/Education/Wojna_Essay.html.

Mehr News Agency. (2011). Internet Price and Speed. Retrieved May 20, 2012, from http://www.mehrnews.com/fa/newsdetail.aspx?NewsID=1188581

Ministry of Education-ICT Section. (2003). Synopsis of ICT activities in Education, Tehran: Ministry of Education.

Montazer, G. H. A. \& Bahreininejad. A. (2004). The E-learning System Dilemmas in Iran. Iranian Journal of Information Science and Technology, 2(1), 11-27.

Moosavi, S. Y. \& Pazooki. R. (2006). E-learning and its Effects on Educational Systems (in Persian). Tehran: Azad University -South.

Nafisi, A. (2003). The Ideal Perspective, Missions, General Aims, Strategies and Policies of ICT in Education, Approved by the Strategic Council of ICT in Education (in Persian), Tehran: NP.

Net Index by Ookla. (2010). Upload Speed. Retrieved Feb 14, 2011, from http://netindex.com.

Rabi, A. R. (2005). Virtual Era Higher Education (e-book), Tabriz, Iran: International University of Iran.

Rivoltella, P. C. (2008). Digital Literacy, London: IGI Publishing.

Safavi, S. A. A., Baveghar, M. \& Ghaffari, H. (2006). Content Production (in Persian), in the Proceedings of Elearning Conference, 25-27 May, Zanjan: Zanjan University Press. 
Sarabpour, S. (2011). Home Internet, Donyaie Eqtesad. Retrieved May 22, 2012, from http://www.donyae-eqtesad.com/Default_view.asp?@=243988

Statistics and Information and Communication Technology Centre. (2011). Situation Report of ICT in Ministry of Education, Tehran: Ministry of Education.

Supreme Council of ICT. (2005). National ICT Agenda (TAKFA); a Brief Report of Action, Tehran: SCICT.

Tabnak (2011). Iran the Most Expensive Internet. Retrieved May 22, 2012, from http://www.tabnak.ir/fa/pages/?cid=63262.

TAKFA (2005). National ICT Agenda, Tehran: Supreme Council of ICT.

Tavakol, M. (2007). Higher Education Development, in the Proceedings of International Conference on Shaping Higher Education, Hangzhou, UNESCO \& Zhejiang University.

Tavakol, M. (2009a). Virtual Research, in the Papers Collection of the First International Conference on Building Research Capacity in Africa, Bamako: UNESCO Cluster Office.

Tavakol, M. (2009b). E-Education in Iran. Iranian Journal of Research in Educational Systems, 3(3).

Wikipedia. (2012a). http://en.wikipedia.org/wiki/history_of_virtual_environment

Yaghoubi, J., Malek-Mohammadi, I., Irvani, H., Attaran, M. \& Gheidi, A. (2008). Virtual Students' Perceptions of E-learning in Iran. Turkish Online Journal of Educational Technology, 7(3).

Zamani, B. E. (2010). Successful Implementation Factors for Using Computers in Iranian Schools During one Decade. Computers and Education Journal, 54(1), 59-68. 